\title{
Electrical and magnetic properties of atomic layer deposited cobalt oxide and zirconium oxide nanolaminates
}

Kristjan Kalam*1, Helina Seemen ${ }^{1}$, Mats Mikkor ${ }^{1}$, Taivo Jõgiaas ${ }^{1}$, Peeter Ritslaid ${ }^{1}$, Aile Tamm$^{1}$, Kaupo Kukli ${ }^{1,2}$, Aarne Kasikov ${ }^{1}$, Joosep Link ${ }^{3}$, Raivo Stern ${ }^{3}$, Salvador Dueñas ${ }^{4}$, Helena Castán ${ }^{4}$

${ }^{1}$ Institute of Physics, University of Tartu, W. Ostwald 1, 50411 Tartu, Estonia.

${ }^{2}$ Department of Chemistry, University of Helsinki, P. O. Box 55, FI-00014 Helsinki, Finland.

${ }^{3}$ National Institute of Chemical Physics and Biophysics, Akadeemia tee 23, 12618 Tallinn, Estonia.

${ }^{4}$ Department of Electronics, University of Valladolid. Paseo Belén, 15. 47011 Valladolid, Spain.

* Corresponding author, e-mail: kristjan.kalam@ut.ee

\section{Abstract}

\section{Introduction}

Nanostructured $\mathrm{Co}_{3} \mathrm{O}_{4}$ in thin film form may possess and demonstrate a variety of properties making the material attractive for several applications. $\mathrm{Co}_{3} \mathrm{O}_{4}$ has been investigated as an important electrode material [1-4], gas sensor [5, 6], catalyst [7, 8], or superhydrophobic coating [9].

$\mathrm{Co}_{3} \mathrm{O}_{4}$ films have demonstrated resistive switching properties potentially enabling their application in resistive random access memory devices [10, 11].

Cobalt oxide, $\mathrm{Co}_{3} \mathrm{O}_{4}$, containing $\mathrm{Co}^{2+}$ and $\mathrm{Co}^{3+}$ ions, is recognized as magnetic semiconductor material [12]. Antiferromagnetic behavior with characteristic magnetization-field curves can be demonstrated by $\mathrm{Co}_{3} \mathrm{O}_{4}$ nanoparticles [13]. Regarding the possible applications in spintronics, it may occur necessary to activate ferromagnetic coupling in $\mathrm{Co}_{3} \mathrm{O}_{4}$ nanoparticles by hybridization with foreign materials, e.g. graphene oxide [14].

$\mathrm{Co}_{3} \mathrm{O}_{4}$ films have been grown by oxidation of electron-beam evaporated Co layers [15], pulsed laser deposition [5, 10] chemical bath deposition [1, 6], chemical solution deposition $[8,11]$, hydrothermal method [2, 13], solvothermal synthesis [9], spray pyrolysis [16] 
Epitaxial thin films of cobalt oxide were grown by atomic layer deposition (ALD) using Co(thd) $)_{2}$ (thd $=2$,2,6,6-tetramethyl-3,5-heptanedionato) and ozone as precursors on singlecrystalline $\mathrm{MgO}(100), \alpha-\mathrm{Al}_{2} \mathrm{O}_{3}(001)$, and $\mathrm{SrTiO}_{3}(100)$ in the temperature range of 138-283 ${ }^{\circ} \mathrm{C}$ [17]. On $\mathrm{MgO}(001)$ and/or $\mathrm{SiO}_{2} / \mathrm{Si}$ substrates, the $\mathrm{Co}_{3} \mathrm{O}_{4}$ have also been grown by ALD in the substrate temperature range of $450-700{ }^{\circ} \mathrm{C}$ from $\mathrm{CoI}_{2}$ and $\mathrm{O}_{2}$ as precursors [18]. Into high aspect ratio substrates $\mathrm{Co}_{3} \mathrm{O}_{4}$ films have been grown by ALD from bis(cyclopentadienyl)cobalt(II), $\mathrm{CoCp}_{2}$, and ozone in the temperature range of $137-331{ }^{\circ} \mathrm{C}$ $[19,20]$. In other ALD processes, $\mathrm{Co}(\mathrm{Cp})_{2}$ was used with ozone probably at $210{ }^{\circ} \mathrm{C}[21]$ or with $\mathrm{O}_{2}$ plasma in the range of $100-400{ }^{\circ} \mathrm{C}$ [22]. $\mathrm{Co}_{3} \mathrm{O}_{4}$ films have later been grown at 120 $300{ }^{\circ} \mathrm{C}$ using bis(1,4-di-iso-propyl-1,4-diazabutadiene)cobalt $\left[\mathrm{C}_{16} \mathrm{H}_{32} \mathrm{~N}_{4} \mathrm{Co}\right.$, Co(dpdab) $]$, and ozone in ALD on $\mathrm{SiO}_{2}$ powder pellets [23], and in the range of $50-150{ }^{\circ} \mathrm{C}$ from cyclopentadienylcobalt dicarbonyl $\left[\left(\mathrm{C}_{5} \mathrm{H}_{5}\right) \mathrm{Co}(\mathrm{CO})_{2}, \mathrm{CpCo}(\mathrm{CO})_{2}\right]$ and ozone on soda lime glass [24]. Carbonyl-based precursors, however, tend to decompose at rather low temperatures around $200{ }^{\circ} \mathrm{C}$. Alumina supported cobalt catalysts were prepared in an ALD process [7], with the cobalt(II)acetylacetonate, $\mathrm{Co}(\mathrm{acac})_{2}$, or cobalt(III)acetylacetonate, $\mathrm{Co}(\mathrm{acac})_{3}$, as precursors, and, after the precursor chemisorption on alumina powders, the acac-ligands were removed using air at $450{ }^{\circ} \mathrm{C}$. $\mathrm{Co}(\mathrm{acac})_{3}$ and $\mathrm{O}_{3}$ have also been used to dope $\mathrm{TiO}_{2}$ films in order to tune their magnetization characteristics [25].

There are very few studies available reporting the growth and characterization of cobaltdoped zirconia. Cobalt-doped $\mathrm{ZrO}_{2}$ films have earlier been prepared by spray pyrolysis [26], microwave-assisted combustion [27] or sol-gel synthesis [28], In certain cases, tendency to saturatively magnetize, and narrow hysteresis behavior has been observed in cobalt-doped zirconia [27, 28].

This study was conducted to investigate the growth and structure of $\mathrm{ZrO}_{2}$ and $\mathrm{Co}_{3} \mathrm{O}_{4}$, when deposited on one-another. Resistive switching characteristics of $\mathrm{ZrO}_{2}-\mathrm{Co}_{3} \mathrm{O}_{4}$ nanolaminates were studied to evaluate if such films could be of interest from the viewpoint of memristor technology. Also, measurements were carried out to determine the polarization characteristics of the samples in the presence of an external magnetic or electric field. The purpose of this was to explore the possibility of these films exhibiting multiferroic behavior.

\section{Experimental details}

The films studied in this work were grown in a low-pressure flow-type ALD reactor [29]. Tris(2,4-pentanedionato)cobalt, 99,9\%, also known as Co(асас)3, supplied by Volatec, Ltd., 
and used as the cobalt precursor, was evaporated at $125{ }^{\circ} \mathrm{C}$ from an half-open glass boat inside the reactor. Zirconium precursor was $99,99 \% \mathrm{ZrCl}_{4}$, supplied by Aldrich. $\mathrm{ZrCl}_{4}$ was evaporated at $162{ }^{\circ} \mathrm{C}$ from an half-open glass boat inside the reactor. Nitrogen, $\mathrm{N}_{2}$ (99.999\% purity, AGA), was applied as the carrier and purging gas. Ozone produced from $\mathrm{O}_{2}(99.999 \%$ purity, AGA) was used as an oxidizer and the ALD reactions were carried out at $300{ }^{\circ} \mathrm{C}$.

Two-layer nanolaminates of $\mathrm{ZrO}_{2}$ and $\mathrm{Co}_{3} \mathrm{O}_{4}$ were deposited in a following manner: $100 \times$ $\mathrm{ZrO}_{2}$ (100 ALD growth cycles of $\left.\mathrm{ZrO}_{2}\right)+200 \times \mathrm{Co}_{3} \mathrm{O}_{4}\left(200\right.$ cycles of $\left.\mathrm{Co}_{3} \mathrm{O}_{4}\right)$. Alternatively, the order of layers was reversed from $\mathrm{ZrO}_{2} / \mathrm{Co}_{3} \mathrm{O}_{4}$ to $\mathrm{Co}_{3} \mathrm{O}_{4} / \mathrm{ZrO}_{2}$. The cycle times for $\mathrm{ZrO}_{2}$ were 5-5-5-5 s for the sequence $\mathrm{ZrCl}_{4}$ pulse $-\mathrm{N}_{2}$ purge $-\mathrm{O}_{3}$ pulse $-\mathrm{N}_{2}$ purge. Cycle times for an analogous $\mathrm{Co}_{3} \mathrm{O}_{4}$ growth cycle were 7-5-5-5 s.

Films were grown on various substrates: Si(100) cleansed and etched [30] and highly-doped conductive Si substrates covered by $10 \mathrm{~nm}$ thick TiN film grown by chemical vapor deposition. The films, which were deposited on TiN substrates for electrical measurements, were also supplied with platinum electrodes electron-beam evaporated on top of the films.

X-ray fluorescence (XRF) spectrometer Rigaku ZSX 400 and program ZSX Version 5.55 was used to measure the elemental composition of films. Spectroscopic ellipsometer (SE), model GES5-E, was used for the measurements of the films thicknesses. The crystal structure was evaluated by grazing incidence X-ray diffractometry (GIXRD), using a X-ray diffractometer SmartLab Rigaku with $\mathrm{CuK} \alpha$ radiation, which corresponds to an $\mathrm{X}$-ray wavelength of $0.15406 \mathrm{~nm}$. Surface morphology of films was evaluated by scanning electron microscopy (SEM) using a Dual Beam equipment FEI Helios NanoLab 600.

Ferroelectricity measurements were done by means of an Agilent DXO-X 3104 digital oscilloscope with a built-in wave generator. The standard Sawyer-Tower experiment was carried out by applying a periodic triangular-shaped stimulus and recording the voltage loops data from the oscilloscope. Charge values were obtained from the sensed voltage across a stated capacitance.

Resistive switching measurements were carried out by means of a semiconductor analyzer Keithley 4200SCS, with samples put in a light-tight and electrically shielded box. The DC voltage was applied to the top electrode, leaving the bottom one grounded. 
Magnetic measurements were performed using Vibrating Sample Magnetometer (VSM) option of the Physical Property Measurement System 14T Quantum Design by scanning the magnetic field from -1 to $1 \mathrm{~T}$ parallel to the film surface at room temperature.

\section{Results and discussion}

\section{Film growth and composition}

ALD reactions were carried out at $300{ }^{\circ} \mathrm{C}$, since reactions for $\mathrm{Co}_{3} \mathrm{O}_{4}$ at $250{ }^{\circ} \mathrm{C}$ and $350{ }^{\circ} \mathrm{C}$ resulted in growth per cycle, which was 50\% and 60\% lower than for samples deposited at $300{ }^{\circ} \mathrm{C}$, respectively. $\mathrm{ZrO}_{2}$ also exhibited the highest growth rate at $300{ }^{\circ} \mathrm{C}$. Evaporator temperature for $\mathrm{Co}(\mathrm{acac})_{3}$ was chosen to be $125{ }^{\circ} \mathrm{C}$, since the deposited amount of cobalt did not increase upon further increasing the temperature (Fig. 1). $\mathrm{Co}_{3} \mathrm{O}_{4}$ deposition consisting of 200 or more ALD cycles resulted in similar growth rates. For a lower amount of ALD cycles, the growth rate to number of cycles is not a linear relationship (Fig. 2). Thickness and composition data is given in Table I. Nanolaminate films were deposited in such a manner that the layers were similar in terms of their thickness.

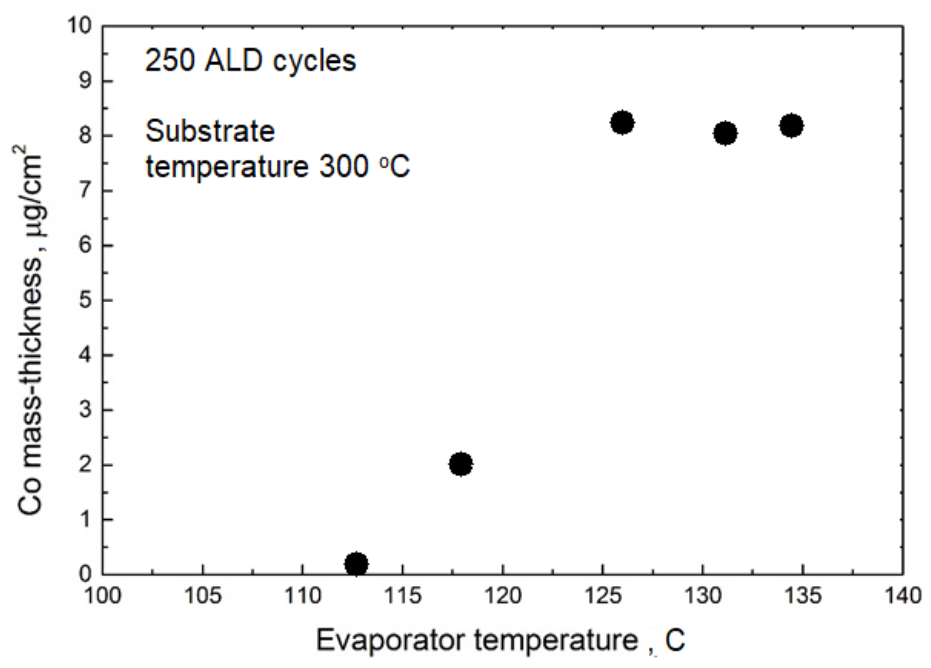

Fig. 1. Mass-thickness of cobalt with respect to evaporator temperature. Each deposition consisted of 250 ALD cycles at $300{ }^{\circ} \mathrm{C}$. The dot diameter covers the error estimation. 


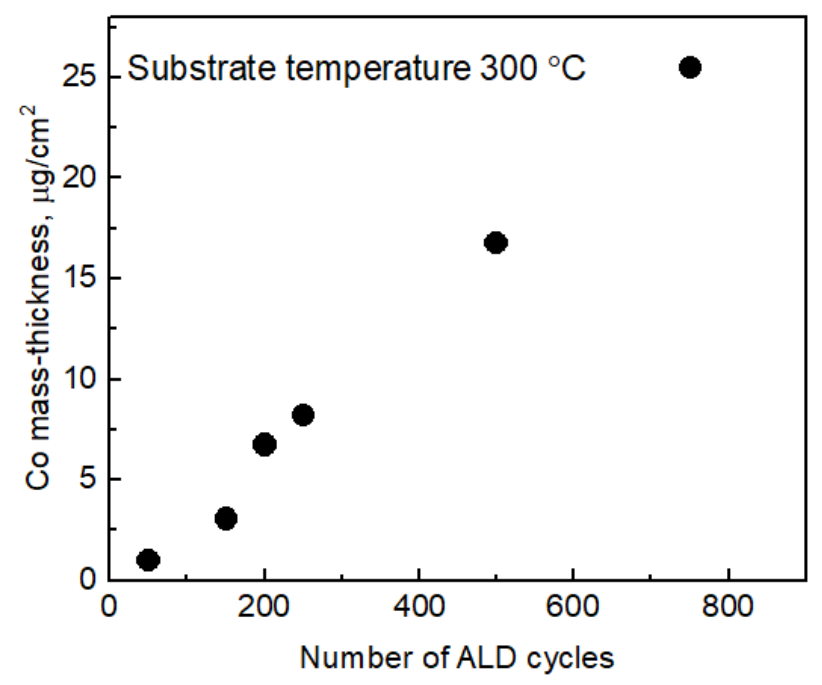

Fig. 2. Mass-thickness of cobalt per cycle with respect to number of ALD cycles. The dot diameter covers the error estimation.

Table I. Thickness and composition data of the samples. $d$ - thickness, GPC - growth per cycle.

\begin{tabular}{|l|l|l|l|l|l|l|l|l|}
\hline & $\mathrm{d}, \mathrm{nm}$ & $\begin{array}{l}\mathrm{d}\left(\mathrm{ZrO}_{2}\right), \\
\mathrm{nm}\end{array}$ & $\begin{array}{l}\mathrm{d}\left(\mathrm{Co}_{3} \mathrm{O}_{4}\right), \\
\mathrm{nm}\end{array}$ & $\begin{array}{l}\text { Cation } \\
\text { ratio, } \\
\mathrm{Zr} / \mathrm{Co}\end{array}$ & $\begin{array}{l}\mathrm{Cl}, \\
\text { wt. \% }\end{array}$ & $\begin{array}{l}\mathrm{C}, \\
\text { wt. \% }\end{array}$ & $\begin{array}{l}\mathrm{GPC} \\
(\mathrm{ZrO}), \\
\mathrm{nm}\end{array}$ & $\begin{array}{l}\mathrm{GPC} \\
\left(\mathrm{Co}_{3} \mathrm{O}_{4}\right), \\
\mathrm{nm}\end{array}$ \\
\hline $\mathrm{ZrO}_{2}$ & 31 & 31 & - & - & 0.4 & - & 0.13 & - \\
\hline $\mathrm{Co}_{3} \mathrm{O}_{4}$ & 15 & - & 15 & - & - & 7.8 & - & 0.06 \\
\hline $\mathrm{ZrO}_{2} / \mathrm{Co}_{3} \mathrm{O}_{4}$ & 24 & 12 & 12 & 0.7 & 0.3 & 5.3 & 0.12 & 0.06 \\
\hline $\mathrm{Co}_{3} \mathrm{O}_{4} / \mathrm{ZrO}_{2}$ & 26 & 14 & 12 & 1.2 & 0.5 & 3.3 & 0.14 & 0.06 \\
\hline
\end{tabular}

\section{Film structure}

GIXRD shows that the films were crystalline, as deposited. The cubic phase of $\mathrm{ZrO}_{2}$ (PDF Card 00-027-0997) is dominant, also some peaks could be assignable to the tetragonal phase, but in the case of given analysis here, such a distinction can not be made with certainty. Small peaks of the monoclinic $\mathrm{ZrO}_{2}$ (PDF Card 00-037-1484) are also detectable in the case of pure $\mathrm{ZrO}_{2}$. Only the cubic phase of $\mathrm{Co}_{3} \mathrm{O}_{4}$ (PDF Card 00-042-1467) can be seen. The nanolaminates exhibit the peaks of both cubic $\mathrm{ZrO}_{2}$ and cubic $\mathrm{Co}_{3} \mathrm{O}_{4}$, although the peaks are 
significantly less intense. This is most likely due to the thickness of nanolaminate layers which is lower than that of the reference single metal oxides (Fig. 3).

Scanning electron microscope images of the film surfaces indicate that, regardless of rather low layer thicknesses, all films are continuous over the surface, without holes or pores visible on the surface and crystallization is also evident (Fig. 4). $\mathrm{Co}_{3} \mathrm{O}_{4}$ film shown on figure 4.a was deposited using 200 ALD deposition cycles. On figure 4.b, a $\mathrm{Co}_{3} \mathrm{O}_{4}$ film is shown, which is deposited with 50 cycles and it can be seen that such a film may not even be continuous, therefore limiting the minimum thickness to which a continuous $\mathrm{Co}_{3} \mathrm{O}_{4}$ film can be deposited.

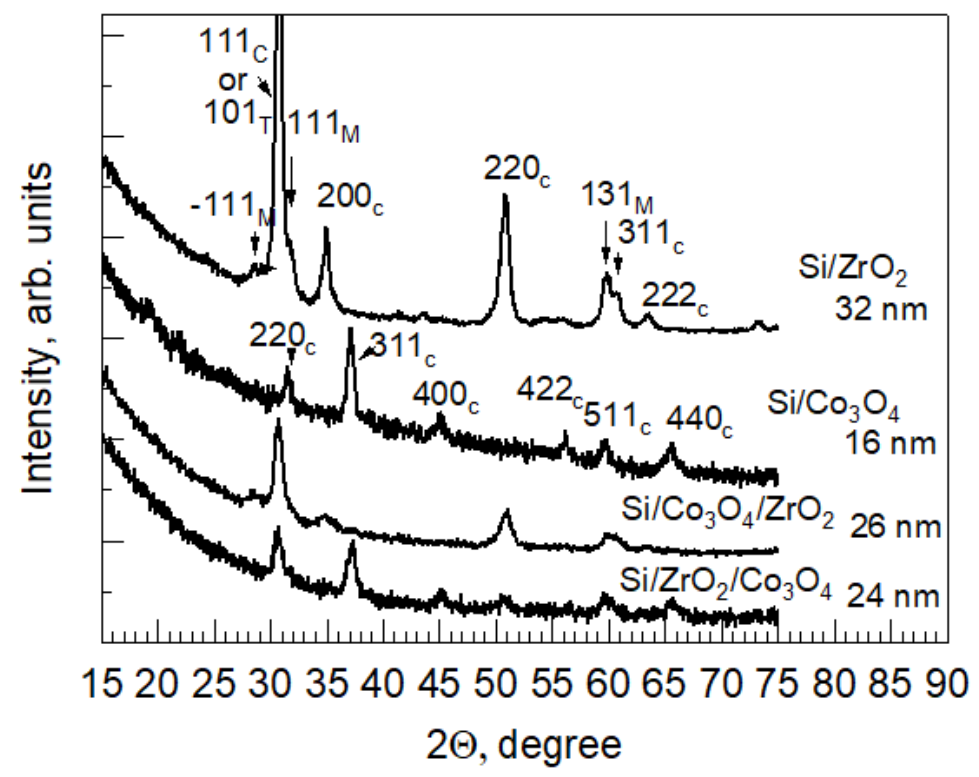

Fig. 3. GIXRD diffractograms for pure $\mathrm{ZrO}_{2}, \mathrm{Co}_{3} \mathrm{O}_{4}$ and two-layer nanolaminates $\mathrm{Co}_{3} \mathrm{O}_{4} / \mathrm{ZrO}_{2}$ and $\mathrm{ZrO}_{2} / \mathrm{Co}_{3} \mathrm{O}_{4}$. The composition and thicknesses of the layers are indicated by the labels at the patterns. Miller indices are attributed to corresponding monoclinic (M) and cubic (C) phases. 

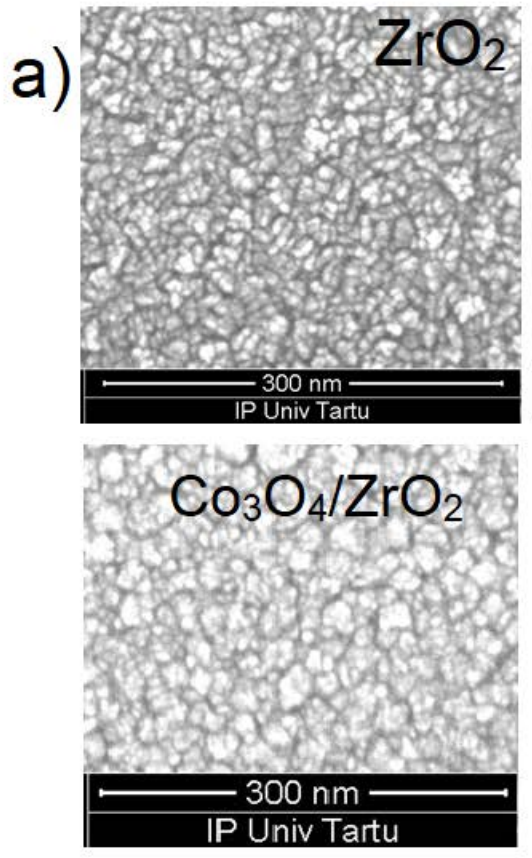
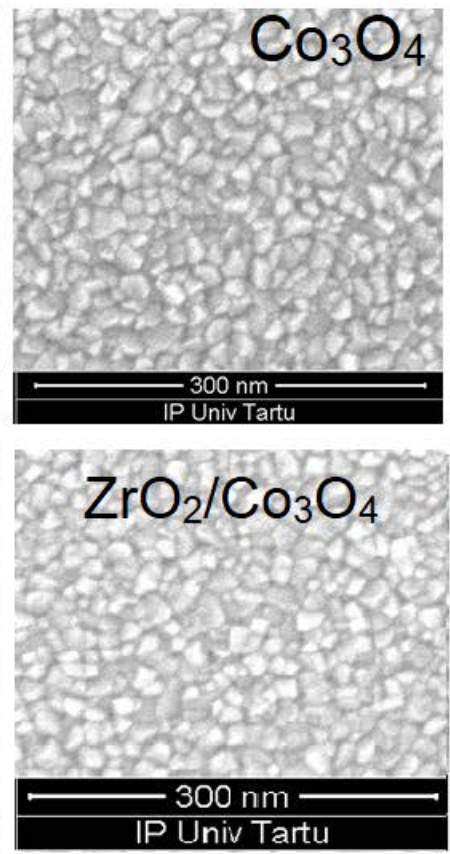
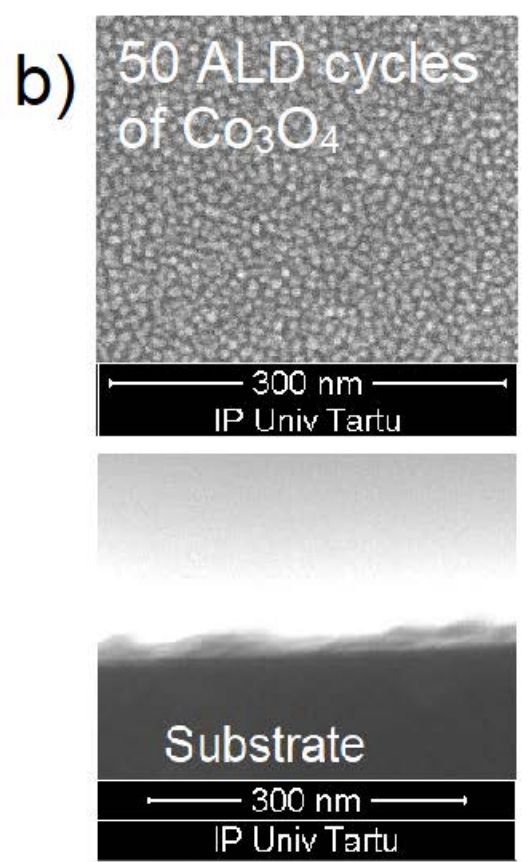

Fig. 4. a) Scanning electron microscope images of zirconium and cobalt oxides in the upper row and nanolaminates with a structure of $\mathrm{Co}_{3} \mathrm{O}_{4} / \mathrm{ZrO}_{2}$ and $\mathrm{ZrO}_{2} / \mathrm{Co}_{3} \mathrm{O}_{4}$, in left and right panels, respectively, in the lower row. b) 50 ALD cycles of $\mathrm{Co}_{3} \mathrm{O}_{4}$ surface on top panel and sideview of the same sample on the bottom panel.

\section{Electrical and magnetic properties}

Figure 5 depicts current-voltage curves from the films described in Table I, measured in resistive switching regime. It can be observed that all samples show bipolar behavior, but with opposite signs (Fig. 5). More specifically, in the films of pure $\mathrm{Co}_{3} \mathrm{O}_{4}$ and $\mathrm{ZrO}_{2} / \mathrm{Co}_{3} \mathrm{O}_{4}$ the transition from high to low resistance state (SET) occurs at negative voltages, whereas the transition from high to low resistance state (RESET) occurs at positive voltages. On the other hand, in the samples of pure $\mathrm{ZrO}_{2}$ and $\mathrm{Co}_{3} \mathrm{O}_{4} / \mathrm{ZrO}_{2}$ SET occurs at positive voltages (Fig. 5). Polarity is expressed as that of Pt dot electrode in relation to TiN/Si.

In both types of nanolaminates, SET is gradual, whereas RESET is very sharp (when RESET occurs, the currents drop sharply). The opposite sign of the bipolar loops can be related to the ordering of the bilayer. The conductive filaments in such materials are formed due to the accumulation of oxygen vacancies, which cluster, thus connecting top and bottom electrodes (SET process). Oxygen vacancies are due to the migration of negative oxygen ions from the dielectric film. RESET process is essentially the opposite mechanism: oxygen anions are 
moved from the metal to the insulator and backfill the vacancies to annihilate the conductive path [31, 32].

Therefore, negative reset voltage values indicate that oxygen atoms coming from the top electrode causes the conductive filament oxidation in the adjacent insulator, that is, in the upper dielectric region. That is the case of sample $\mathrm{Co}_{3} \mathrm{O}_{4} / \mathrm{ZrO}_{2}$. In sample $\mathrm{ZrO}_{2} / \mathrm{Co}_{3} \mathrm{O}_{4}$, reset occurs for positive voltages, i.e., due to oxygen ions coming from the bottom electrode to the bottom dielectric region ( $\mathrm{ZrO}_{2}$ as well). In summary, filaments are broken and refilled at the $\mathrm{ZrO}_{2}$ film (the free energy oxidation energy is more negative for $\mathrm{ZrO}_{2}$ than for $\mathrm{Co}_{3} \mathrm{O}_{4}$ ). The resistance ratio of the high- and low- resistance states was 35 for the $\mathrm{Co}_{3} \mathrm{O}_{4} / \mathrm{ZrO}_{2}$ film. For other films this ratio was 3-4. Resistance states were compared at a voltage of $0.5 \mathrm{~V}$.

All samples exhibited certain charge polarization, as shown in Figure 6. Although in the case of pure $\mathrm{ZrO}_{2}$, the charge polarization values were insignificant, compared to other samples. Charge polarization was about $1 \mathrm{nC}$ at $0 \mathrm{~V}$, for $\mathrm{ZrO}_{2}$. With no applied voltage, the $\mathrm{Co}_{3} \mathrm{O}_{4}$ sample exhibited a charge polarization value of $1.5 \cdot 10^{5} \mathrm{nC}$, and $4.0 \cdot 10^{4} \mathrm{nC}$ for the nanolaminates. The charge polarization - applied voltage loops observed here are not quite attributable to ferroelectric behavior. Even if ferroelectric effect is contributing, it is overwhelmed by other effects, such as interfacial polarization. Saturation level for charge polarization was not achieved at either polarity of the external field, as the polarized charge kept increasing with the voltage. An argument on behalf of leakage current being responsible for the charge polarization has been given by Kalam, et al [30] in the case of iron oxide doped $\mathrm{ZrO}_{2}$. According to Scott [33], such charge polarization to voltage curves could not be attributed to ferroelectricity. For comparison to literature data, Lin et al. [34] has demonstrated charge-field loops from orthorhombic $\mathrm{ZrO}_{2}$ grown by plasma-assisted ALD between Pt electrodes, resembling those characteristic of a ferroelectric material.

All samples were magnetized in the presence of an external magnetic field and exhibited fast nonlinear saturative magnetization, which is generally characteristic of a ferromagnetic material. Coercivity values of films were low, ranging from 20-150 Oe, resulting in very narrow hysteresis loops. Saturation magnetization values ranged from $1 \cdot 10^{-6}$ emu to $4 \cdot 10^{-6}$ emu (Fig. 7).

Relative permittivity of pure $\mathrm{ZrO}_{2}$ film in this work is 26 (Fig. 8). Zhao and Vanderbilt [35] have shown that cubic $\mathrm{ZrO}_{2}$ has an averaged relative permittivity of 36.8 and monoclinic 19.7. Assuming all of our film to be crystalline and exhibit only cubic and monoclinic phases, this 
should imply that our film consists of $63 \%$ monoclinic and $37 \%$ cubic phase. Since the GIXRD analysis shows mostly cubic, possibly tetragonal and very little monoclinic phase, we can only assume that the film is not fully crystalline, but somewhat amorphous with regions of mostly cubic crystal lattice. In the case of pure $\mathrm{Co}_{3} \mathrm{O}_{4}$ the experimentally measured permittivity value is slightly higher at low frequency (approximately 30) and diminishes as frequency increases. Nanolaminates exhibited higher permittivity values than each of the pure oxide films separately (Fig. 8). This is possibly due to a larger portion of the films being crystalline. On the other hand, the space charge region created at the interface between both oxide layers has as final effect the reduction of the effective insulator thickness, dealing an apparent reduction of the permittivity. Besides, samples containing $\mathrm{Co}_{3} \mathrm{O}_{4}$ exhibit a more significative variation of the permittivity with the frequency. This seems indicate that the dipolar relaxation of $\mathrm{Co}_{3} \mathrm{O}_{4}$ is greater than that of $\mathrm{ZrO}_{2}$.

Refractive index values and dispersion are given on figure 9. Garcia et al. [36] have found the refractive index of $\mathrm{Co}_{3} \mathrm{O}_{4}$ to be 2.48 at $633 \mathrm{~nm}$. This is very similar to our result, however comparing the shape of dispersion function is not possible, since they have only reported the refractive index at a certain wavelength. Al-Maiyaly [37], Ekwealor et al. [38] and Gençyılmaz et al. [39] have reported similar refractive index values for $\mathrm{Co}_{3} \mathrm{O}_{4}$ and also similar shapes of the dispersion functions as are shown on figure 9. 

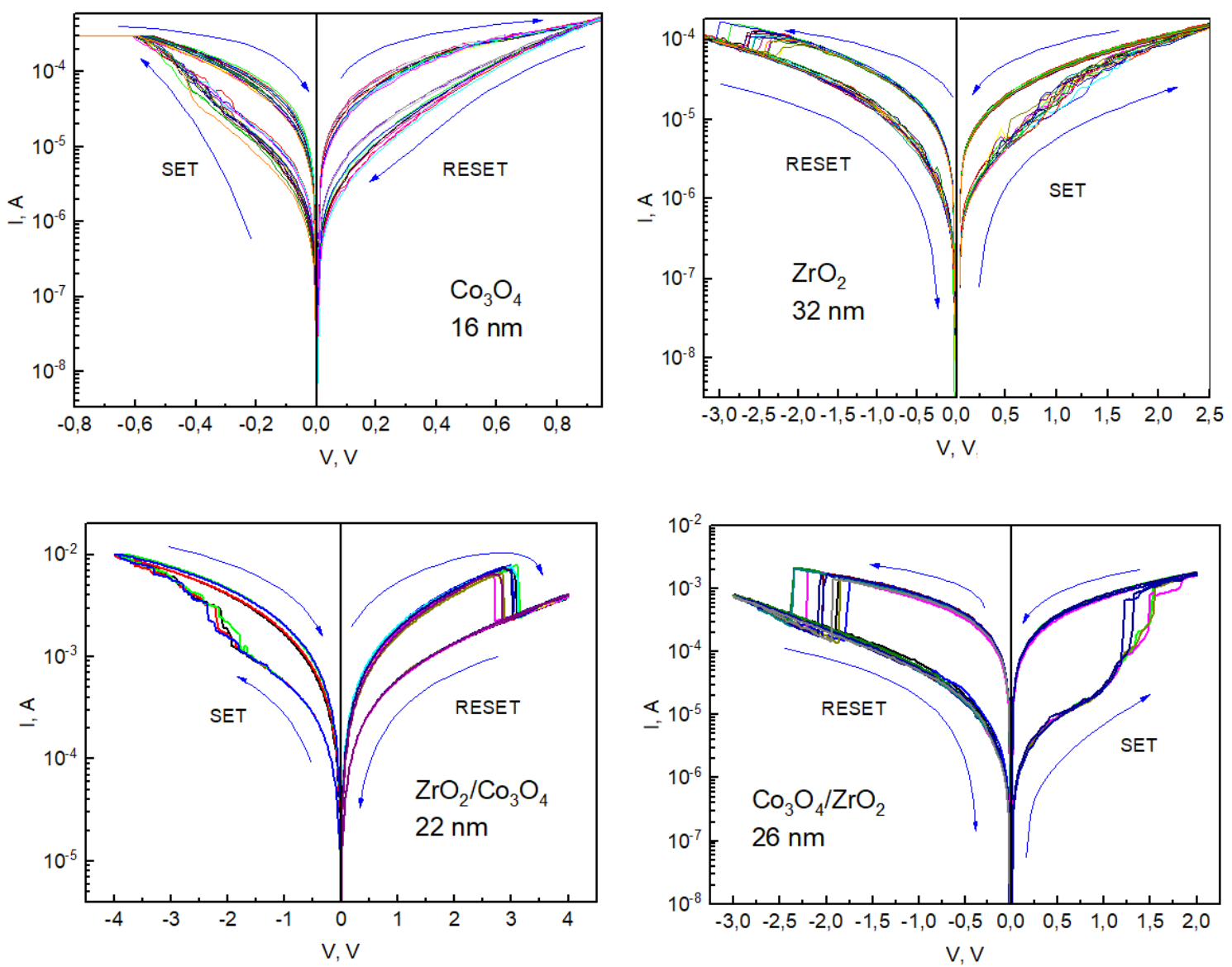

Fig. 5. Resistive switching cycles for metal oxides described by Table I. The composition and thickness of the metal oxide layers are indicated by labels. 

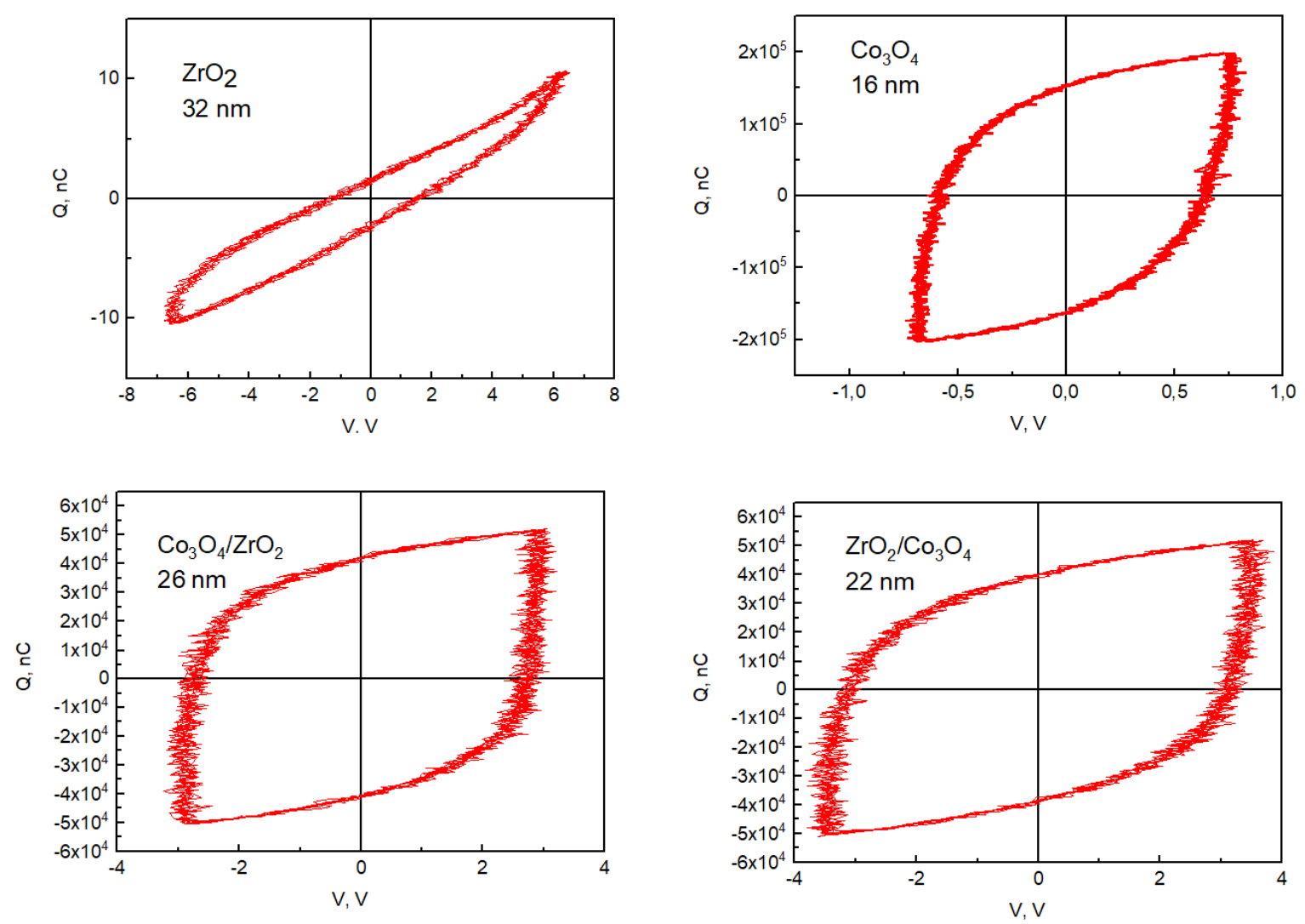

Fig. 6. Charge polarization versus applied voltage curves. The composition and thickness of the metal oxide layers are indicated by labels. 


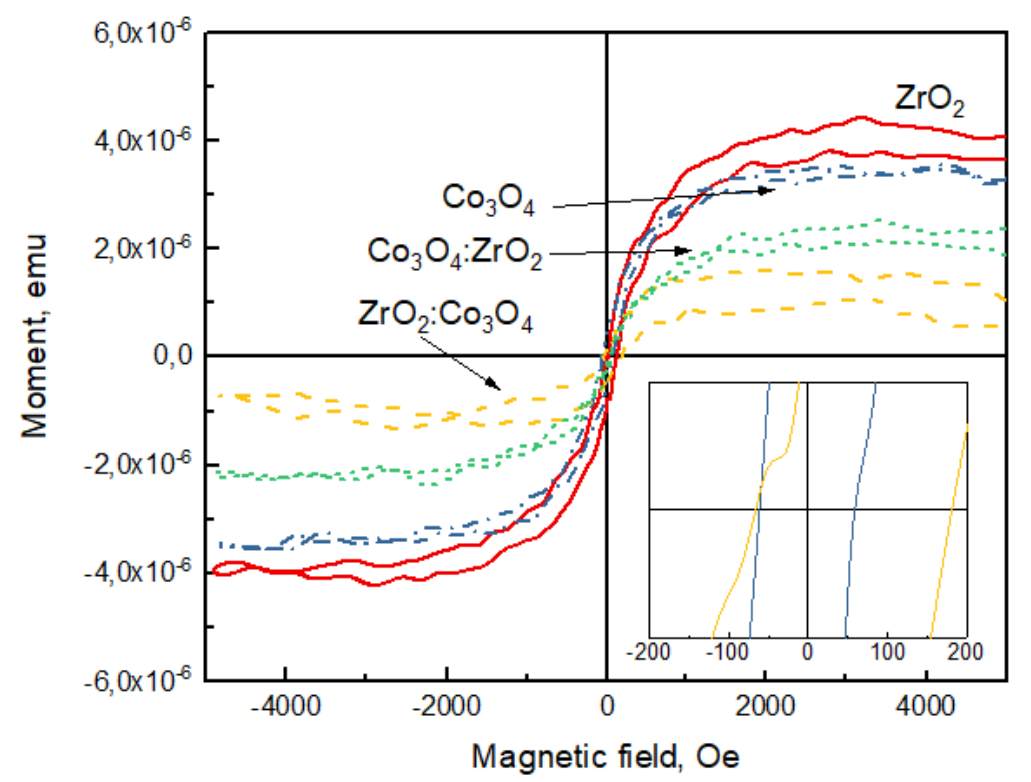

Fig. 7. Magnetization to applied magnetic field curves measured at room temperature for metal oxides described by Table I. Panel in the lower right corner shows the coercivity values

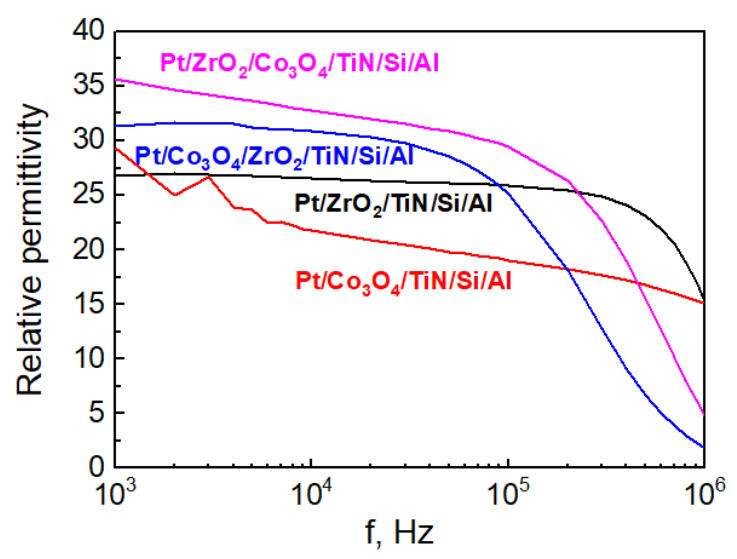

for two samples at a larger scale.

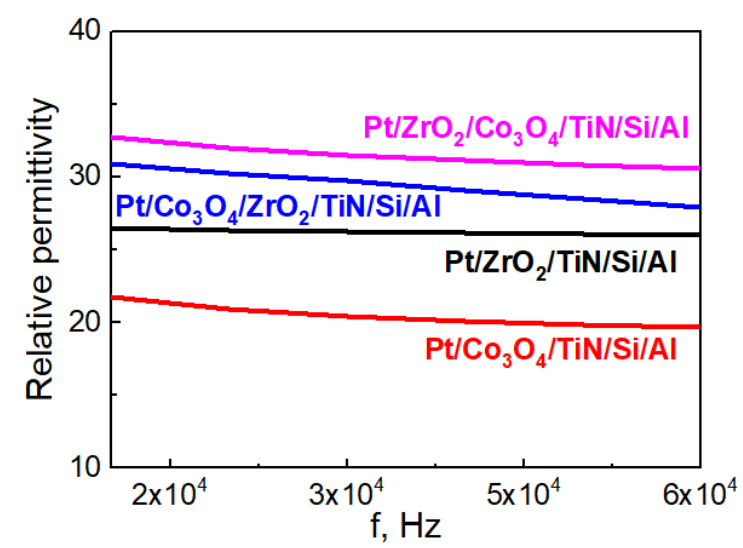

//SD.//Remove second

Figure in this panel//SD

Fig. 8. Relative permittivity curves measured for metal oxides described by Table I. The composition of the functional layers, as well as the electrodes and the substrate, are indicated by labels. 

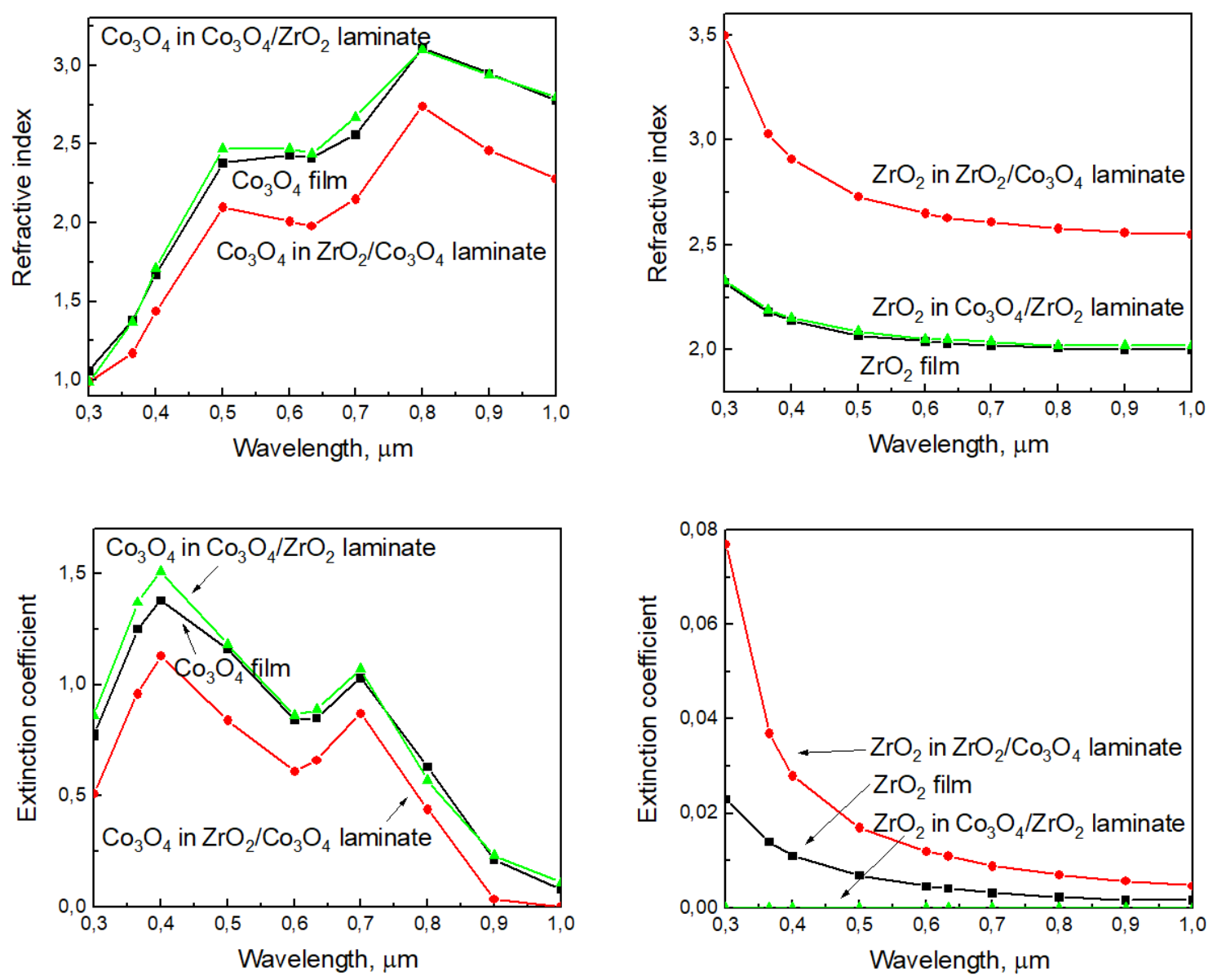

Fig. 9. Dispersion of $\mathrm{Co}_{3} \mathrm{O}_{4}$ on the left panels and $\mathrm{ZrO}_{2}$ on the right panels. Top panels show the dispersion of refractive index, bottom panels show the dispersion of extinction coefficient.

\section{Summary}

$\mathrm{ZrO}_{2}-\mathrm{Co}_{3} \mathrm{O}_{4}$ nanolaminates were deposited by ALD, using $\mathrm{ZrCl}_{4}, \mathrm{Co}(\mathrm{acac})_{3}$ and $\mathrm{O}_{3}$. All films exhibited room-temperature saturation magnetization, charge polarization and resistive switching characteristics to some extent, in their as-deposited state. Values for saturation magnetization ranged from $1 \cdot 10^{-6}$ to $4 \cdot 10^{-6}$ emu. Charge polarization values at $0 \mathrm{~V}$ were 4.0 $10^{4} \mathrm{nC}$ for the nanolaminates and the resistance ratio of the high- and low- resistance states was 35 for the $\mathrm{Co}_{3} \mathrm{O}_{4} / \mathrm{ZrO}_{2}$ film. Relative permittivity and dispersion functions for the studied films were also presented.

\section{Acknowledgements}


The present study was partially funded by the European Regional Development Fund project "Emerging orders in quantum and nanomaterials" (TK134), Spanish Ministry of Economy and Competitiveness (TEC2014-52152-C3-3-R) with support of Feder funds, Estonian Academy of Sciences (SLTFYPROF), and the Estonian Research Agency (IUT2-24, PRG4).

\section{References}

1. Y. Li, K. Huang, Z. Yao, S. Liu, X. Qing, $\mathrm{Co}_{3} \mathrm{O}_{4}$ thin film prepared by a chemical bath deposition for electrochemical capacitors, Electrochim. Acta 56 (2011) 2140-2144. http://dx.doi.org/10.1016/j.electacta.2010.11.074

2. S. Wu, T. Xia, J. Wang, F. Lu, C. Xu, X. Zhang, L. Huo, H. Zhao, Ultrathin mesoporous $\mathrm{Co}_{3} \mathrm{O}_{4}$ nanosheets-constructed hierarchical clusters as high rate capability and long life anode materials for lithium-ion batteries, Appl. Surf. Sci. 406 (2017) 46-55. http://dx.doi.org/10.1016/j.apsusc.2017.02.107

3. Z. Lu, J. Ding, X. Lin, Y. Liu, H. Ye, G. Yang, F. Yin, B. Yan, Low-temperature synthesis of two-dimensional nanostructured $\mathrm{Co}_{3} \mathrm{O}_{4}$ and improved electrochemical properties for lithium-ion batteries, Powder Technology $309 \quad$ (2017) 22-30. http://dx.doi.org/10.1016/j.powtec.2016.12.081

4. R. Vittal, K.-C. Ho, Cobalt oxide electrodes-problem and a solution through a novel approach using cetyltrimethylammonium bromide (CTAB), Catal. Rev. 57 (2015) 145-191, http://dx.doi.org/10.1080/01614940.2015.1035192

5. I.Kärkkänen, A. Floren, H. Mändar, T. Avarmaa, R. Jaaniso, Modelling and characterisation of $\mathrm{Co}_{3} \mathrm{O}_{4}$ thin film gas sensors, Procedia Chemistry 1 (2009) 654-657. http://dx.doi.org/10.1016/j.proche.2009.07.163

6. C.-W. Kung, C.-Y. Lin, T.-J. Li, R.Vittal, K.-C. Ho, Synthesis of $\mathrm{Co}_{3} \mathrm{O}_{4}$ thin films by chemical bath deposition in the presence of different anions and application to $\mathrm{H}_{2} \mathrm{O}_{2}$ sensing, Procedia Engineering 25 (2011) 847-850. http://dx.doi.org/0.1016/j.proeng.2011.12.208

7. L.B. Backman, A. Rautiainen, M. Lindblad, A. O. I. Krause, The interaction of cobalt species with alumina on $\mathrm{Co} / \mathrm{Al}_{2} \mathrm{O}_{3}$ catalysts prepared by atomic layer deposition, Applied Catalysis A: General 360 (2009) 183-191. http://dx.doi.org/10.1016/j.apcata.2009.03.020 
8. H. S. Jeon, M. S. Jee, H. Kim, S. J. Ahn, Y. J. Hwang, B. K. Min, Simple chemical solution deposition of Co3O4 thin film electrocatalyst for oxygen evolution reaction, ACS Appl. Mater. Interfaces 7 (2015) 24550-24555. http://dx.doi.org/10.1021/acsami.5b06189

9. C. Jiang, W. Li, A facile method for preparations of micro-nanotextured $\mathrm{Co}_{3} \mathrm{O}_{4}$ films with the excellent superhydrophobic and anti-icing behavior, Mater. Lett. 122 (2014) 133-138. http://dx.doi.org/10.1016/j.matlet.2014.02.015

10. X. Gao, H. Guo, Y. Xia, J. Yin, Z. Liu, Unipolar resistive switching characteristics in $\begin{array}{llllll}\mathrm{Co}_{3} \mathrm{O}_{4} & \text { films, } & \text { Thin } & \text { Solid } & \text { Films } & 519\end{array}$ $\underline{\text { http://dx.doi.org/10.1016/j.tsf.2010.07.075 }}$

11. W. Hu, L. Zou, X. Lin, C. Gao, Y. Guo, D. Bao, Unipolar resistive switching effect and mechanism of solution-processed spinel $\mathrm{Co}_{3} \mathrm{O}_{4}$ thin films, Materials and Design 103 (2016) 230-235. http://dx.doi.org/10.1016/j.matdes.2016.04.070

12. J. Chen, X. Wu, A. Selloni, Electronic structure and bonding properties of cobalt oxide in the spinel structure, Phys. Rev. B $83 \quad$ (2011) 245204. http://dx.doi.org/10.1103/PhysRevB.83.245204

13. F. Moro, S. V. Y. Tang, F. Tuna, E. Lester, Magnetic properties of cobalt oxide nanoparticles synthesised by a continuous hydrothermal method, J. Magn. Magn. Mater. 348 (2013) 1-7. http://dx.doi.org/10.1016/j.jmmm.2013.07.064

14. L. Chen, F. Hu, H. Duan, Q. Liu, H. Tan, W. Yan, T. Yao, Y. Jiang, Z. Sun, S. Wei, Intrinsic ferromagnetic coupling in $\mathrm{Co}_{3} \mathrm{O}_{4}$ quantum dots activated by graphene hybridization, Appl. Phys. Lett. 108 (2016) 252402. http://dx.doi.org/10.1063/1.4954715

15. M. De Santis, A. Buchsbaum, P. Varga, M. Schmid, Growth of ultrathin cobalt oxide films on Pt(111), Phys. Rev. B $84 \quad$ (2011) 125430. http://dx.doi.org/10.1103/PhysRevB.84.125430

16. S. Z. Abbas, A. A. Aboud, M. Irfan, S. Alam, Effect of substrate temperature on structure and optical properties of $\mathrm{Co}_{3} \mathrm{O}_{4}$ films prepared by spray pyrolysis technique, IOP Conf. Series: Mater. Sci. Eng. 60 (2014) 012058. http://dx.doi.org/10.1088/1757-899X/60/1/012058

17. K. B. Klepper, O. Nilsen, H. Fjellvåg, Epitaxial growth of cobalt oxide by atomic layer deposition, J. Crystal Growth $307 \quad$ (2007) 457-465. http://dx.doi.org/10.1016/j.jcrysgro.2007.06.028 
18. M. Rooth, E. Lindahl, A. Hårsta, Atomic layer deposition of $\mathrm{Co}_{3} \mathrm{O}_{4}$ thin films using a $\mathrm{CoI}_{2} / \mathrm{O}_{2}$ precursor combination, Chem. Vap. Deposition 12 (2006) 209-213. http://dx.doi.org/10.1002/cvde.200506447

19. M. Diskus, O. Nilsen, H. Fjellvåg, Thin films of cobalt oxide deposited on high aspect ratio supports by atomic layer deposition, Chem. Vap. Deposition 17 (2011) 135-140. http://dx.doi.org/10.1002/cvde.201006891

20. B. Huang, K. Cao, X. Liu, L. Qian, B. Shan, R. Chen, Tuning the morphology and composition of ultrathin cobalt oxide films via atomic layer deposition, RSC Adv. 5 (2015) 71816-71823. http://dx.doi.org/10.1039/c5ra09782g

21. S. C. Riha, Benjamin M. Klahr, E. C. Tyo, S. Seifert, S. Vajda, M. J. Pellin, T. W. Hamann, A. B. F. Martinson, Atomic layer deposition of a submonolayer catalyst for the enhanced photoelectrochemical performance of water oxidation with hematite, ACS Nano 7 (2013) 2396-2405. http://dx.doi.org/10.1021/nn305639z

22. M. E. Donders, H. C. M. Knoops, M. C. M. van de Sanden, W. M. M. Kessels, P. H. L. Notten, Remote plasma atomic layer deposition of $\mathrm{Co}_{3} \mathrm{O}_{4}$ thin films, J. Electrochem. Soc. 158 (2011) G92-G96. http://dx.doi.org/10.1149/1.3552616

23. B. Han, J.-M. Park, K. H. Choi, W.-K. Lim, T. R. Mayangsari, W. Koh, W.-J. Lee, Atomic layer deposition of stoichiometric $\mathrm{Co}_{3} \mathrm{O}_{4}$ films using bis(1,4-di-iso-propyl-1,4diazabutadiene) cobalt, Thin Solid Films $589 \quad$ (2015) 718-722. $\underline{\text { http://dx.doi.org/10.1016/j.tsf.2015.07.003 }}$

24. B. Han, K. H. Choi, J. M. Park, J. W. Park, J. W. Jung, W.-J. Lee, Atomic layer deposition of cobalt oxide thin films using cyclopentadienylcobalt dicarbonyl and ozone at low temperatures, J. Vac. Sci. Technol. A $31 \quad$ (2013) 01A145. http://dx.doi.org/10.1116/1.4772461

25. V. Pore, M. Dimri, H. Khanduri, R. Stern, J. Lu, L. Hultman, K. Kukli, M. Ritala, M. Leskelä, Atomic layer deposition of ferromagnetic cobalt doped titanium oxide thin films, Thin Solid Films 519 (2011) 3318-3324. http://dx.doi.org/10.1016/j.tsf.2011.01.191

26. S. A. Hussain, A. H. O. A. lkhayatt, E. A. Mahdi, Effect of Co-dopant on the structural and optical properties of nanocrystalline $\mathrm{ZrO}_{2}$ thin films prepared by spray pyrolysis technique, IOSR J. Appl. Phys. 8 (2016) 44-49. http://dx.doi.org/10.9790/4861-0805014449 
27. T. R. Sahoo, S. S. Manoharan, S. H. Lim, L. G. Salamanca-Riba, Structural and magnetic properties of cubic zirconia/Co composites synthesized by microwave route, Synthesis and Reactivity in Inorganic, Metal-Organic, and Nano-Metal Chemistry, 38 (2008) 280-283. http://dx.doi.org/10.1080/15533170802023452

28. J. Okabayashi, S. Kono, Y. Yamada, K. Nomura, Fabrication and magnetic properties of Fe and Co co-doped ZrO2, AIP Adv. 1 (2011) 042138. http://dx.doi.org/10.1063/1.3662044

29. T. Arroval, L. Aarik, R. Rammula, V. Kruusla, J. Aarik, Effect of substrate-enhanced and inhibited growth on atomic layer deposition and properties of aluminum-titanium oxide films, Thin Solid Films 600 (2016) 119-125. http://dx.doi.org/10.1016/j.tsf.2016.01.024

30. K. Kalam, H. Seemen, P. Ritslaid, M. Rähn, A. Tamm, K. Kukli, A. Kasikov, J. Link, R. Stern, S. Dueñas, H. Castán, H. García, Atomic layer deposition and properties of ZrO2/Fe2O3 thin films, Beilstein J. Nanotechnol. 9 (2018) 119-128. http://dx.doi.org/10.3762/bjnano.9.14

31. D. Ielmini, Resistive switching memories based on metal oxides: mechanisms, reliability and scaling, Semicond. Sci. Technol. $31 \quad$ (2016) $063002 \quad$ (25pp). http://dx.doi.org/10.1088/0268-1242/31/6/063002

32. F. Pan, C. Chen, Z. Wang, Y. Yang, J. Yang, F. Zeng, Nonvolatile resistive switching memories-characteristics, mechanisms and challenges, Progress in Natural Science: Materials International 20(2010) 01-15.

33. J. F. Scott, Ferroelectrics go bananas, J. Phys.: Condens. Matter 20 (2008) 021001, http://dx.doi.org/10.1088/0953-8984/20/02/021001

34. B.-T. Lin, Y.-W. Lu, J. Shieh, M.-J. Chen, Induction of ferroelectricity in nanoscale $\mathrm{ZrO}_{2}$ thin films on Pt electrode without post-annealing. J. Eur. Ceram. Soc. 37 (2017) 1135-1139. http://dx.doi.org/10.1016/j.jeurceramsoc.2016.10.028

35. X. Zhao, D. Vanderbilt, Phonons and lattice dielectric properties of zirconia. Physical Review B 65 (2002), 075105. http://dx.doi.org/10.1103/PhysRevB.65.075105

36. H. A. Garcia, R. P. de Melo Jr., A. Azevedo, C. B. de Araújo, Optical and structural characterization of iron oxide and cobalt oxide thin films at $800 \mathrm{~nm}$. Appl. Phys. B 111 (2013), 313-321. https://doi.org/10.1007/s00340-013-5335-3 
37. B. K. H. Al-Maiyaly, Study the Effect of Thickness on the Electrical Conductivity and Optical Constant of $\mathrm{Co}_{3} \mathrm{O}_{4}$ Thin Films. Ibn Al-Haitham Jour. for Pure \& Appl. Sci. 26 (1) (2013), 159-166.

38. A. B. C. Ekwealor, S. U. Offiah, S. C. Ezugwu, and F. I. Ezema, Variations of Optical and Structural Properties of $\mathrm{Co}_{\mathrm{x}} \mathrm{O}_{\mathrm{y}}$ Thin Films with Thermal Treatment, Indian Journal of Materials Science, vol. 2014, Article ID 367950, 5 pages, (2014). https://doi.org/10.1155/2014/367950

39. O. Gençyılmaz, T. Taşköprü, F. Atay, İ. Akyüz, Synthesis, characterization and ellipsometric study of ultrasonically sprayed $\mathrm{Co}_{3} \mathrm{O}_{4}$ films, Appl. Phys. A 121 (2015) 1, 245254. https://doi.org/10.1007/s00339-015-9417-4 